\title{
Modification of Commercial Activated Carbons for $\mathrm{CO}_{2}$ Adsorption
}

\author{
J. Sreńscek-Nazzal*, U. NArkiewicz, A.W. MoraWski, R. Wróbel, \\ A. Gęsikiewicz-Puchalska and B. MichalkiewiCZ
}

The West Pomeranian University of Technology in Szczecin, Institute of Chemical and Environment Engineering, K. Pułaskiego 10, 70-322 Szczecin, Poland

(Received July 3, 2015; in final form December 10, 2015)

\begin{abstract}
The aim of the investigations was a modification of DTO, a commercial activated carbon (AC), to improve $\mathrm{CO}_{2}$ adsorption capacity. The adsorption of $\mathrm{CO}_{2}$ up to 40 bar at $40^{\circ} \mathrm{C}$ temperature was investigated. The volumetric method was applied for $\mathrm{CO}_{2}$ adsorption isotherm measurements. The starting material - DTO — was modified using chemical activation $\left(\mathrm{KOH}, \mathrm{ZnCl}_{2}, \mathrm{~K}_{2} \mathrm{CO}_{3}\right)$. The textural parameters of all the ACs were determined by nitrogen adsorption at the liquid nitrogen temperature of $-196{ }^{\circ} \mathrm{C}$ on Quadrasorb SI. Results showed that the AC modified with $\mathrm{KOH}$ had the highest $S_{\mathrm{BET}}, V_{\text {tot }}, V_{\text {mic }}$ values of $2063 \mathrm{~m}^{2} / \mathrm{g}, 1.13 \mathrm{~cm}^{3} / \mathrm{g}$, and $0.67 \mathrm{~cm}^{3} / \mathrm{g}$, respectively. ACs with a wider pore size distribution (from micropores to mesopores) were obtained. The maximum $\mathrm{CO}_{2}$ adsorption was equal to $14.44 \mathrm{mmol} / \mathrm{g}$ for DTO/KOH - modified carbon whereas $8.07 \mathrm{mmol} / \mathrm{g}$ of $\mathrm{CO}_{2}$ was adsorbed at DTO. The $\mathrm{CO}_{2}$ adsorption capacities of the ACs were found to be closely correlated with the BET surface areas of the materials tested. The experimental data was fitted to the Freundlich, Langmuir, Sips and Toth equations to determine the model isotherm. The Sips model was found to be the best for fitting the adsorption of $\mathrm{CO}_{2}$.
\end{abstract}

DOI: 10.12693/APhysPolA.129.394

PACS/topics: 81.05.U-, 68.43.-h

\section{Introduction}

Carbon dioxide is considered as the major greenhouse gas. The increased $\mathrm{CO}_{2}$ concentration in the atmosphere due to emissions from fossil fuel combustion has caused concerns about climate changes [1]. Now, a wide range of techniques including, conversion to useful chemicals [2] adsorption [3], absorption [4] and membranes [5] have been suggested to sequestrate $\mathrm{CO}_{2}$ from fuel gases. Adsorption is thought by many scientists to be a promising and economical technique due to its low energy requirement, cost effectiveness, and ease of use at a wide variety of temperatures and pressures [6].

Thus, the interest in the capture of greenhouse gases inevitably involves the development of inexpensive porous materials, including highly microporous AC. The principal problem is to produce microporous adsorbents with high $\mathrm{CO}_{2}$ adsorption capacity and high $\mathrm{CO}_{2}$ selectivity at different temperatures, stable adsorption capacity of carbon dioxide after repeated adsorption/desorption cycles, stability during extensive adsorption-desorption cycles, and low production costs. Activated carbons have an advantage over other adsorbents because of their high thermal stability and low raw material costs. AC can be formed from a variety of materials, including coals, industrial by-products, and wood or other biomass sources [7,8]. Activated carbon is mainly produced by physical and chemical activation.

*corresponding author; e-mail: jsrenscek@zut.edu.pl
Physical activation is usually carried out using carbon dioxide, steam, air, or their mixture. Chemical activation involves various agents such as $\mathrm{ZnCl}_{2}[9], \mathrm{KOH}[3,10,11]$ and $\mathrm{K}_{2} \mathrm{CO}_{3}[12]$. Adsorption performance of $\mathrm{AC}$ depends on the pore structure and surface properties. ACs obtained by chemical activation often possess high surface area and well developed micropores, which makes them attractive materials for $\mathrm{CO}_{2}$ adsorption $[13,14]$. There is an extensive body of literature on the use of carbonbased adsorbents for $\mathrm{CO}_{2}$ capture. Table I presents the adsorption of $\mathrm{CO}_{2}$ on different carbon materials prepared by different methods.

Results presented in Table I show that it is possible to obtain ACs with a relatively high $\mathrm{CO}_{2}$ adsorption capacity using different preparation methods. However, due to different activation conditions used in various studies, it is difficult to compare preparation methods. Therefore, further studies are necessary to systematize the influence of chemical activation parameters, e.g. an activating agent, on obtaining $\mathrm{ACs}$ useful in $\mathrm{CO}_{2}$ adsorption.

The aim of this study was to modify commercial DTO - activated carbon for $\mathrm{CO}_{2}$ adsorption by chemical activation of $\mathrm{KOH}, \mathrm{K}_{2} \mathrm{CO}_{3}$ and $\mathrm{ZnCl}_{2}$. The influence of the activating agent on the texture and $\mathrm{CO}_{2}$ adsorption capacity was investigated. The measured adsorption isotherms were then correlated to the Langmuir, Freundlich, Sip and Toth adsorption models, which are widely utilized for modeling the adsorption of microporous materials.

\section{Sample preparation}

DTO, a commercial AC, supplied by Gryfskand Sp. z o.o. Hajnówka, Poland was used as the precursor of 
carbon in the present study. The starting material was modified by chemical activation. DTO was treated with $\mathrm{KOH}, \mathrm{ZnCl}_{2}, \mathrm{~K}_{2} \mathrm{CO}_{3}$ using an impregnation method. The concentration of $\mathrm{ZnCl}_{2}$ and $\mathrm{K}_{2} \mathrm{CO}_{3}$ in water was $20 \%$ whereas a saturated solution of $\mathrm{KOH}$ was used. The mass ratio of DTO:KOH was 1:3. Per one gram of precursor $2 \mathrm{~cm}^{3}$ of $\mathrm{ZnCl}_{2}$ and $\mathrm{K}_{2} \mathrm{CO}_{3}$ solutions were used. The soaking time was $3 \mathrm{~h}$. The mixtures were dried for $19 \mathrm{~h}$ at $200^{\circ} \mathrm{C}$. The dried samples were then pyrolyzed in a horizontal electric furnace at a temperature of $800^{\circ} \mathrm{C}$, holding time of $1 \mathrm{~h}$ and heating rate of $10^{\circ} \mathrm{C} \mathrm{min}-1$. After pyrolysis, the ACs were cooled down to room temperature in a flow of $\mathrm{N}_{2}$ and then removed from the furnace. The resulting ACs were repeatedly washed with water. Subsequent to this, a $5 \mathrm{M}$ solution of $\mathrm{HCl}$ was used to remove the residual activating agent. The ACs were rinsed with distilled water until the carbon was free of chloride ions. Finally, the samples were dried at $200^{\circ} \mathrm{C}$ for $12 \mathrm{~h}$. They were then named as DTO $/ \mathrm{KOH}, \mathrm{DTO} / \mathrm{K}_{2} \mathrm{CO}_{3}$ and $\mathrm{DTO} / \mathrm{ZnCl}_{2}$.

\section{TABLE I}

$\mathrm{CO}_{2}$ uptake on different carbon materials.

\begin{tabular}{c|c|c|c|c}
\hline \hline Precursor & Preparation methods & $\begin{array}{c}\text { Adsorption } \\
\text { conditions }\end{array}$ & $\begin{array}{c}\mathrm{CO}_{2} \text { uptake } \\
{[\mathrm{mmol} / \mathrm{g}]}\end{array}$ & Ref. \\
\hline WG12 & activation with $\mathrm{KOH}$ & $40^{\circ} \mathrm{C}, 1 \mathrm{bar}$ & 2.1 & {$[3]$} \\
WG12 & activation with $\mathrm{ZnCl}_{2}$ & $40{ }^{\circ} \mathrm{C}, 1 \mathrm{bar}$ & 1.6 & {$[3]$} \\
coal tar pitch & carbonization & $25{ }^{\circ} \mathrm{C}, 1 \mathrm{bar}$ & 2.2 & {$[15]$} \\
petroleum coke & carbonization-activation $(\mathrm{KOH})$ & $25^{\circ} \mathrm{C}, 1 \mathrm{bar}$ & 3.5 & {$[16]$} \\
Petroleum pitch & carbonization-activation $(\mathrm{KOH})$ & $25{ }^{\circ} \mathrm{C}, 1$ bar & 4.7 & {$[17]$} \\
anthracite & carbonization-activation $(\mathrm{steam})$ & $30^{\circ} \mathrm{C}, 1$ bar & 1.5 & {$[18]$} \\
carpet & carbonization-activation $(\mathrm{KOH})$ & $25^{\circ} \mathrm{C}, 1$ bar & 1.9 & {$[19]$} \\
almond shell & carbonization-activation $\left(\mathrm{CO}_{2}\right)$ & $25^{\circ} \mathrm{C}, 1$ bar & 2.6 & {$[20]$} \\
olive stones & carbonization-activation $\left(\mathrm{CO}_{2}\right)$ & $25^{\circ} \mathrm{C}, 1$ bar & 2.4 & {$[21]$} \\
soybean & carbonization-activation $\left(\mathrm{ZnCl}_{2} / \mathrm{CO}_{2}\right)$ & $30^{\circ} \mathrm{C}, 0.15$ bar & 0.93 & {$[22]$} \\
urea and formaldehyde & carbonization-activation $\left(\mathrm{K}_{2} \mathrm{CO}_{3}\right)$ & $25^{\circ} \mathrm{C}, 1$ bar & 1.8 & {$[23]$} \\
Pocahontas & dry coal & $22^{\circ} \mathrm{C}, 1$ bar & 0.4 & {$[24]$} \\
North Dakota & dry coal & $22^{\circ} \mathrm{C}, 1$ bar & 0.1 & {$[24]$} \\
Illinois & dry subbituminous coal & $22^{\circ} \mathrm{C}, 1$ bar & 0.3 & {$[24]$}
\end{tabular}

\section{Sample characterization}

The porous texture characterization of all the modified ACs was carried out by physical $\mathrm{N}_{2}$ adsorption/desorption at $77 \mathrm{~K}$ using a Quadrasorb automatic system (Quantachrome Instruments). The samples were degassed overnight $(12 \mathrm{~h})$ under high vacuum (final pressure of $10^{-4}$ Torr) at $250^{\circ} \mathrm{C}$.

The Brunauer-Emmett-Teller (BET) equation was used to determine surface areas $\left(S_{\mathrm{BET}}\right)$. The $S_{\mathrm{BET}}$ were determined in the relative pressure range of $0.05-0.2$. The total pore volume, $V_{\mathrm{p}}$, was calculated from the volume of nitrogen held at the highest relative pressure $\left(p / p_{0}=0.99\right)$. The volume of micropore, $V_{\text {mic }}$, was estimated using the density functional theory (DFT). The volume of mesopores, $V_{\text {mes }}$, was estimated by the subtraction of micropore volume from the total amount of pores.

The Fourier transform infrared (FTIR) spectra were obtained using a Nicollet 380 (Thermo Scientific) spectrometer. The spectra were recorded in the range of 400$4000 \mathrm{~cm}^{-1}$ wave number with a resolution of $1 \mathrm{~cm}^{-1}$. The samples for infrared studies were prepared by mixing a given sample with $\mathrm{KBr}$ crystals.
Scanning electron microscopy (SEM) was used to investigate the morphology of the ACs.

The ACs were characterized by the Raman spectroscopy. The Raman spectra were obtained on a Renishaw InVia system using a $785 \mathrm{~nm}$ laser as the excitation source.

Carbon dioxide sorption measurements were performed using the Sieverts apparatus (Hiden Isochem IMI). The accuracy accuracies of pressure and temperature measurements was $\pm 0.05 \%$ of the range for set-point regulation and $\pm 1{ }^{\circ} \mathrm{C}$, respectively. Samples were first degassed at $250^{\circ} \mathrm{C}$ under vacuum of $1 \times 10^{-6}$ mbar and $\mathrm{CO}_{2}$ was adsorbed at $40^{\circ} \mathrm{C}$.

Mathematical methods are very useful for thermodynamics [3] and kinetics model [25] solving.

$\mathrm{CO}_{2}$ adsorption data on activated carbons were fitted to the Langmuir, Freundlich, Sips and Toth standard isotherm models.

The Langmuir adsorption isotherm assumes that adsorption takes place at specific homogeneous sites and is the simplest and still the most useful method. The Langmuir equation can be written as (1) [11, 26]:

$$
q=\frac{q_{\mathrm{m}} b p}{1+b p}
$$


where $q$ is the adsorbed quantity (mmol of $\mathrm{CO}_{2}$ per $\mathrm{g}$ of $\mathrm{AC}), p$ is the pressure of $\mathrm{CO}_{2}$ in the bulk gas phase, $q_{\mathrm{m}}$ is the maximum adsorption capacity $\left(\mathrm{mmol} \mathrm{g}^{-1}\right)$ and $b$ is the Langmuir constant $\left(\right.$ bar $\left.^{-1}\right)$.

The Freundlich isotherm is an empirical equation used to describe heterogeneous systems. The Freundlich equation can be given by $(2)[11,26]$ :

$$
q=k_{\mathrm{F}} p^{n-1},
$$

where $k_{\mathrm{F}}$ is the Freundlich constant and $n$ is the empirical constant associated with the adsorption driving force.

The Sips adsorption isotherm model is a combined form of the Langmuir and Freundlich models/methods. The Sips adsorption equation is commonly given by the following nonlinear Eq. (3) [27, 28]:

$$
q=\frac{q_{\mathrm{m}}(b p)^{1 / n}}{1+(b p)^{1 / n}}
$$

where $q_{\mathrm{m}}$ is the maximum adsorption capacity, $b$ is the Langmuir constant that is related to the apparent energy of sorption, and $n$ is the Freundlich exponent.

The Toth isotherm model, is another empirical equation developed to improve Langmuir isotherm fitting. Toth formulated a three-parameter equation. The Toth isotherm is a model useful in describing heterogeneous adsorption systems, which satisfies both low and highend boundaries of the concentration. The Toth isotherm is expressed as Eq. (4) [27, 29]:

$$
q=\frac{q_{\mathrm{m}}(b p)}{\left[1+(b p)^{t}\right]^{1 / t}},
$$

where $q_{\mathrm{m}}$ is the maximum adsorption capacity, $b$ is the adsorption affinity, and $t$ is the Toth constant.

Isotherm parameters were obtained through a nonlinear fit of experimental data to the model equations using a MatCad software, version 15. In order to evaluate the fit of an isotherm to experimental equilibrium data, algorithms based on the Levenberg-Marquardt were used.

Error functions were defined to enable the optimization process to determine and evaluate the fit of an isotherm equation to experimental data. The error functions employed were as follows:

1. The correlation coefficient $\left(R^{2}\right)[30]$ :

$$
R^{2}=\frac{\sum\left(q_{\mathrm{e}, \text { meas }}-\overline{q_{\mathrm{e}, \text { calc }}}\right)^{2}}{\sum\left(q_{\mathrm{e}, \text { meas }}-\overline{q_{\mathrm{e}, \text { calc }}}\right)^{2}+\left(q_{\mathrm{e}, \text { meas }}-q_{\mathrm{e}, \text { calc }}\right)^{2}},
$$

where $q_{\mathrm{e}, \text { calc }}$ is the calculated adsorbed quantity and $q_{\mathrm{e}, \text { meas }}$ is the experimentally measured adsorbed quantity.

The quality of an isotherm fit to experimental data is typically assessed based on the magnitude of the correlation coefficient for regression, i.e. the isotherm giving an $R^{2}$ value closest to unity is deemed to provide the best fit. $R^{2}$ has a value from 0 to $1(0-100 \%)$.

2. The sum of the squares of errors (SSE) [31]:

$$
S S E=\sum_{i=1}^{p}\left(q_{\mathrm{e}, \mathrm{calc}}-q_{\mathrm{e}, \mathrm{meas}}\right)^{2},
$$

where $q_{\mathrm{e}, \text { calc }}$ is the calculated adsorbed quantity and $q_{\mathrm{e}, \mathrm{meas}}$ is the experimentally measured adsorbed quantity.
The most commonly used, the sum of the squares of errors (SSE) function, has a major drawback in that it provides isotherm parameters showing a better fit at the higher end of the adsorbate concentration. This is because the magnitude of the errors and hence the square of the errors increases as the adsorbate concentration increases.

3. The hybrid fractional error function (HYBRID) [31]:

$$
\text { HYBRID }=\frac{100}{p-n} \sum_{i=1}^{p}\left[\frac{\left(q_{\mathrm{e}, \text { meas }}-q_{\mathrm{e}, \mathrm{calc}}\right)^{2}}{q_{\mathrm{e}, \text { meas }}}\right],
$$

where $q_{\mathrm{e}, \text { calc }}$ is the calculated adsorbed quantity and $q_{\mathrm{e}, \mathrm{meas}}$ is the experimentally measured adsorbed quantity, $n$ is the number of data points and $p$ is the number of parameters within the isotherm equation.

The hybrid fractional error function (HYBRID) was developed in order to improve the fit of the SSE method at low concentration values by dividing the measured value. In addition, a divisor was included as a term for the number of degrees of freedom for the system - the number of data points $(n)$ minus the number of parameters $(p)$ within the isotherm equation.

4. The Marquardt percent standard deviation (MPSD) [32]:

$$
\operatorname{MPSD}=100 \sqrt{\frac{1}{p-n} \sum_{i=1}^{p}\left(\frac{q_{\mathrm{e}, \text { meas }}-q_{\mathrm{e}, \mathrm{calc}}}{q_{\mathrm{e}, \text { meas }}}\right)^{2}},
$$

where $q_{\mathrm{e}, \text { calc }}$ is the calculated adsorbed quantity and $q_{\mathrm{e}, \mathrm{meas}}$ is the experimentally measured adsorbed quantity, $n$ is the number of data points and $p$ is the number of parameters within the isotherm equation.

It is similar in some respects to the geometric mean error distribution modified according to the number of degrees of freedom of the system.

5. The average relative error (ARE) [31]:

$$
\mathrm{ARE}=\frac{100}{p} \sum_{i=1}^{p}\left|\frac{q_{\mathrm{e}, \text { calc }}-q_{\mathrm{e}, \text { meas }}}{q_{\mathrm{e}, \text { meas }}}\right|,
$$

where $q_{\mathrm{e}, \text { calc }}$ is the calculated adsorbed quantity and $q_{\mathrm{e}, \text { meas }}$ is the experimentally measured adsorbed quantity, $p$ is the number of parameters within the isotherm equation.

This error function attempts to minimize the fractional error distribution across the entire concentration range.

6 . The chi-square value is given as [33]:

$$
\chi^{2}=\sum_{i=1}^{i=N} \frac{\left(q_{\mathrm{e}, \text { meas }}-q_{\mathrm{e}, \mathrm{calc}}\right)^{2}}{q_{\mathrm{e}, \mathrm{calc}}},
$$

where $q_{\mathrm{e}, \mathrm{calc}}$ is the calculated adsorbed quantity and $q_{\mathrm{e}, \text { meas }}$ is the experimentally measured adsorbed quantity.

\section{Results and discussion}

4.1. Pore structure development

Adsorption-desorption isotherms of $\mathrm{N}_{2}$ of the modified ACs are shown in Fig. 1. As can be seen from Fig. 1, the volume of adsorbed $\mathrm{N}_{2}$ at a relative pressure close to 0.1 increased depending on the active agent 
and was the largest on $\mathrm{DTO} / \mathrm{KOH}$ - modified carbon. The $\mathrm{N}_{2}$ adsorption capacity at the $P / P_{0}$ close to unity increased from 407 to $732 \mathrm{~cm}^{3} \mathrm{STP} / \mathrm{g}$ for pristine DTO and $\mathrm{DTO} / \mathrm{KOH}$, respectively.

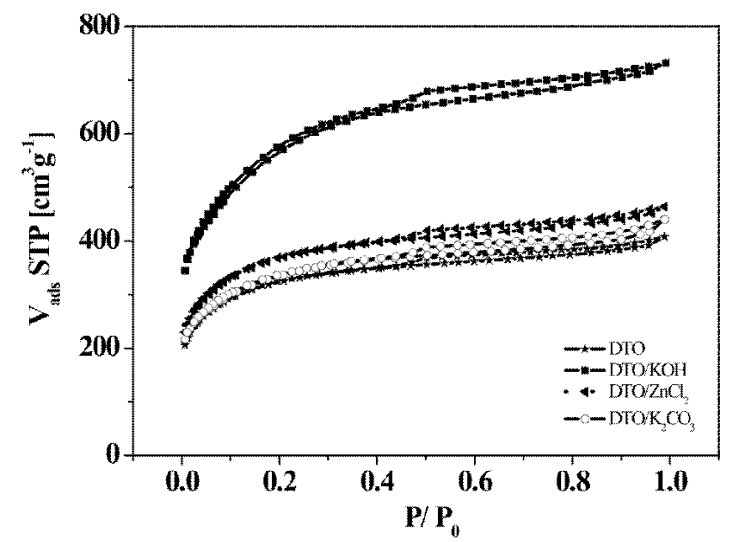

Fig. 1. Adsorption isotherms of nitrogen for DTOactivated carbons.

The type of an activating agent did not have a significant influence on the shape of $\mathrm{N}_{2}$ adsorption-desorption isotherms. All isotherms did not reach a horizontal plateau at high relative pressure. The slope of the curve gradually increased and the isotherms exhibited hysteresis loops. Thus, the isotherms appear to become a combination of types I and IV according to IUPAC classification and, for the isotherms modified with $\mathrm{KOH}$ and $\mathrm{ZnCl}_{2}$ they moved toward a type IV isotherm. This can be attributed to a degree of mesoporosity, which is proved by the mesopore volume in Table II. The characteristic features of type IV isotherm is its hysteresis loop, which is associated with capillary condensation taking place in mesopores. The hysteresis loop exists in the high relative region $\left(P / P_{0}>0.50\right)$. This isotherm exhibits a type $\mathrm{H} 3$ hysteresis loop. For type H3, the loop has plate-like particles giving rise to slit-shaped pores [9].

The textural parameters (BET surface area, total pore volume, micropore volume and mesopore volume) of the DTO - activated carbon are listed in Table II.

TABLE II

Textural parameters derived from $\mathrm{N}_{2}$ adsorption on AC.

\begin{tabular}{c|c|c|c|c}
\hline \hline \multirow{2}{*}{$\mathrm{A}$} & $S_{\mathrm{BET}}$ & $V_{\mathrm{p}}$ & $V_{\text {mic }}$ & $V_{\text {mes }}$ \\
\cline { 2 - 5 } & {$\left[\mathrm{m}^{2} / \mathrm{g}\right]$} & \multicolumn{3}{|c}{$\left[\mathrm{cm}^{3} / \mathrm{g}\right]$} \\
\hline $\mathrm{DTO}$ & 1187 & 0.631 & 0.411 & 0.219 \\
$\mathrm{DTO} / \mathrm{KOH}$ & 2063 & 1.132 & 0.674 & 0.457 \\
$\mathrm{DTO} / \mathrm{ZnCl}_{2}$ & 1353 & 0.718 & 0.464 & 0.254 \\
$\mathrm{DTO} / \mathrm{K}_{2} \mathrm{CO}_{3}$ & 1224 & 0.532 & 0.374 & 0.158
\end{tabular}

The specific surface area of the ACs increased following the chemical modifications. The highest surface area of $2063 \mathrm{~m}^{2} / \mathrm{g}$ was achieved by $\mathrm{KOH}$ activation. The ACs prepared with $\mathrm{K}_{2} \mathrm{CO}_{3}$ and $\mathrm{ZnCl}_{2}$ had a smaller BET surface area compared to DTO/KOH activated carbons, but larger than that of pristine DTO.
The total pore volume increased depending on the activating agent. The maximum micropore volume was achieved on carbon DTO modified with $\mathrm{KOH}$ and it equaled $1.13 \mathrm{~cm}^{3} / \mathrm{g}$. This AC also had the highest mesopore volume. These values are much higher than those obtained for the $\mathrm{K}_{2} \mathrm{CO}_{3}$ and $\mathrm{ZnCl}_{2}$ - activated carbons.

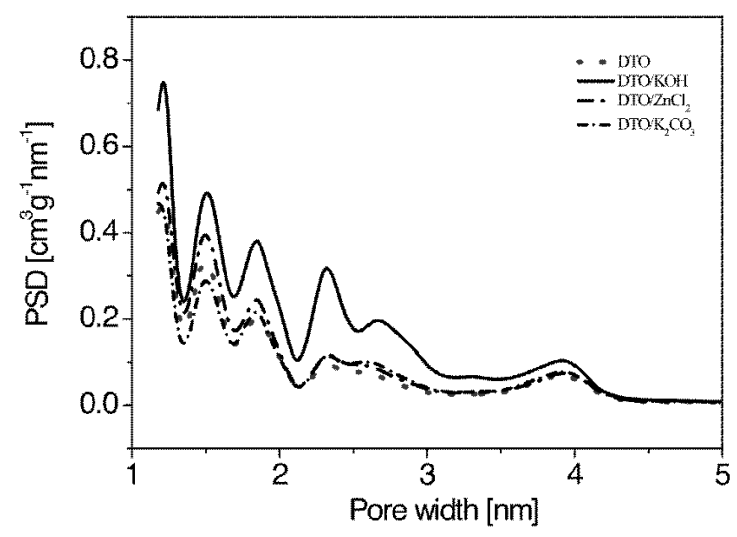

Fig. 2. PSDs obtained by applying the DFT theory to $\mathrm{N}_{2}$ adsorption data at $77 \mathrm{~K}$.

Figure 2 shows the micro- and mesopore size distribution of the ACs. In order to make the graph clearer, the maximum value on the $x$-axis is $5 \mathrm{~nm}$, because the ACs did not contain larger pores. As shown in Fig. 2, the activated carbons contained both micro- and mesopores. However, the micropore volumes are larger than mesopore volumes for all ACs. The ratio of micropore volume to the total pore volume, $V_{\text {micro }} / V_{\mathrm{p}}$, ranged between 0.595 and 0.703 . The activating agent influenced the textural characteristics of the prepared ACs. The use of $\mathrm{KOH}$ as an activation agent increased the BET surface area, microporosity and mesoporosity. More mesopores were created in DTO $/ \mathrm{KOH}$-modified carbon compared to that modified with $\mathrm{ZnCl}_{2}$ and $\mathrm{K}_{2} \mathrm{CO}_{3}$.

\subsection{FTIR analysis}

The chemical nature of the functional groups on the AC surface was identified with FTIR (Fig. 3).

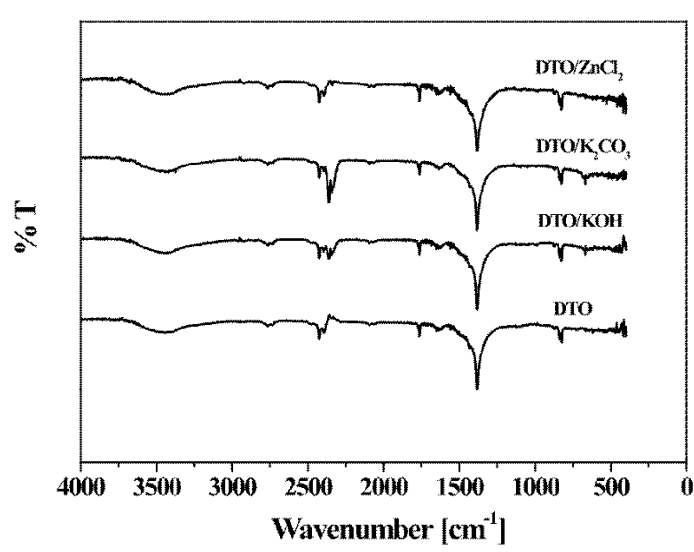

Fig. 3. FTIR spectra of DTO-activated carbons. 
Figure 3 shows that irrespective of the activation agent the overall shapes of the FTIR spectra are very similar. All spectra show peaks characteristic of the $\mathrm{OH}$ group at 3460 and $1640 \mathrm{~cm}^{-1}$. The broader peaks centered at $3460 \mathrm{~cm}^{-1}$ are $\mathrm{OH}$ stretching vibrations of surface hydroxyl groups. The absorption peaks at $1640 \mathrm{~cm}^{-1}$ are due to physically adsorbed water molecules ( $\mathrm{H}-\mathrm{O}-$ H) [34]. All the spectra showed a band in the region of $2360-2344 \mathrm{~cm}^{-1}$ due to the atmospheric $\mathrm{CO}_{2}$ [35]. The broader peaks about $1760 \mathrm{~cm}^{-1}$ were characteristic of $\mathrm{C}=\mathrm{O}$ stretching vibration in carboxylic groups [36]. The peaks around $1380 \mathrm{~cm}^{-1}$ were observed for all ACs and can be assigned to the deformation vibrations of an $\mathrm{H}-\mathrm{C}-\mathrm{OH}$ group [37]. The intensity of the $\mathrm{H}-\mathrm{C}-$ $\mathrm{OH}$ group slightly increases for the $\mathrm{DTO} / \mathrm{KOH}$ and $\mathrm{DTO} / \mathrm{K}_{2} \mathrm{CO}_{3}$ carbons. Contrary to this, the bands located around $820 \mathrm{~cm}^{-1}$ could be assigned to the $\mathrm{C}-\mathrm{H}$ group.

The FTIR spectra of carbons modified with $\mathrm{KOH}$, $\mathrm{K}_{2} \mathrm{CO}_{3}$ and $\mathrm{ZnCl}_{2}$ do not exhibit any significant differences compared to those of DTO carbon. This suggests that the adsorption capacity of activated carbon is not dependent on the chemical reactivity of functional groups at the surface. Thus, the increase in $\mathrm{CO}_{2}$ adsorption capacity is connected with an increase of its surface area and micropore volume. It can be assumed that the $\mathrm{CO}_{2}$ adsorption onto AC was mostly a physical adsorption.

\subsection{The Raman spectroscopy study}

The Raman spectroscopy is one of the most important techniques for characterizing carbon materials. The information on the crystallographic disorder in carbons can also be obtained by the Raman spectroscopy. The Raman spectra of the modified AC samples are shown in Fig. 4. All the spectra have been normalized to the intensity of the $D$ band. The $G$ and $D$ peak positions and the $I_{\mathrm{D}} / I_{\mathrm{G}}$ intensity ratio are widely used for identification of the type and for characterization of the structure of amorphous carbons [38].

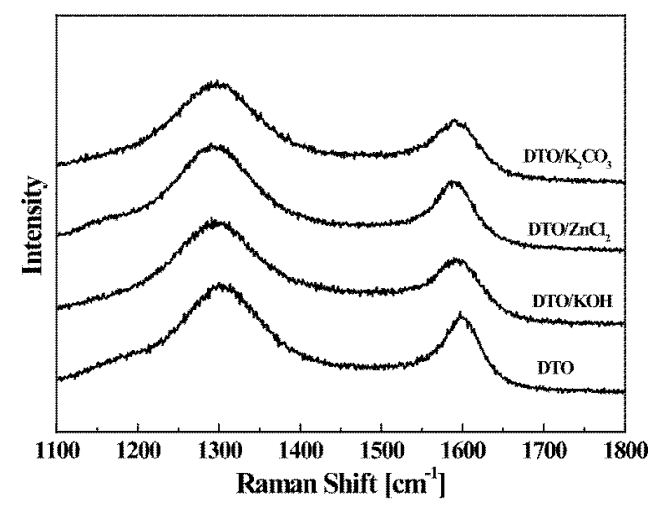

Fig. 4. Raman spectra of DTO-activated carbons.

In Fig. 4 two peaks are observed near 1350 and $1585 \mathrm{~cm}^{-1}$ corresponding to $D$ and $G$ bands, respectively. The $D$-peak $\left(1350 \mathrm{~cm}^{-1}\right)$ corresponds to the amorphous domains when the $G$-peak $\left(1585 \mathrm{~cm}^{-1}\right)$ relates to the graphite domains $[39,40]$. The higher intensity of the $G$ band indicates the higher degree of crystallinity/graphitization. The $D$ band at $1348 \mathrm{~cm}^{-1}$ is due to the disordered portion of the carbons [41-43]. Figure 4 shows that the height of the $D$-peak becomes higher than that of the $G$-peak for all carbon samples.

The intensity ratio of $D$ and $G$ peaks $\left(I_{\mathrm{D}} / I_{\mathrm{G}}\right)$ is used to characterize the degree of carbon materials, i.e., a smaller ratio of $I_{\mathrm{D}} / I_{\mathrm{G}}$ corresponds to a higher degree of $\mathrm{AC}$ graphitization. The $I_{\mathrm{D}} / I_{\mathrm{G}}$ ratio value is varies depending on the activating agent. The $I_{\mathrm{D}} / I_{\mathrm{G}}$ ratio values obtained from the Raman spectroscopy are presented in Table III.

\section{TABLE III}

The $\mathrm{D} / \mathrm{G}$ intensity ratio values obtained from Raman spectroscopy.

\begin{tabular}{c|c}
\hline \hline $\mathrm{AC}$ & $I_{\mathrm{D}} / I_{\mathrm{G}}$ \\
\hline $\mathrm{DTO}$ & 1.36 \\
$\mathrm{DTO} / \mathrm{KOH}$ & 1.46 \\
$\mathrm{DTO} / \mathrm{ZnCl}_{2}$ & 1.44 \\
$\mathrm{DTO} / \mathrm{K}_{2} \mathrm{CO}_{3}$ & 1.45
\end{tabular}

The ratio of $D$-peak to $G$-peak $\left(I_{\mathrm{D}} / I_{\mathrm{G}}\right)$ was the highest for $\mathrm{DTO} / \mathrm{KOH}$-activated carbon (1.46), indicating that the structural disorder (amorphousness) was the highest in this carbon.

\subsection{SEM analysis of activated carbons}

Scanning electron microscopy technique was used to investigate the surface physical morphology of the ACs. Figure $5 \mathrm{a}-\mathrm{d}$ shows SEM photographs of pristine DTO and DTO-modified carbons. Significant differences were observed between the surface morphologies of pristine DTO and the DTO $/ \mathrm{KOH}, \mathrm{DTO} / \mathrm{ZnCl}_{2}, \mathrm{DTO} / \mathrm{K}_{2} \mathrm{CO}_{3}-$ modified carbons.

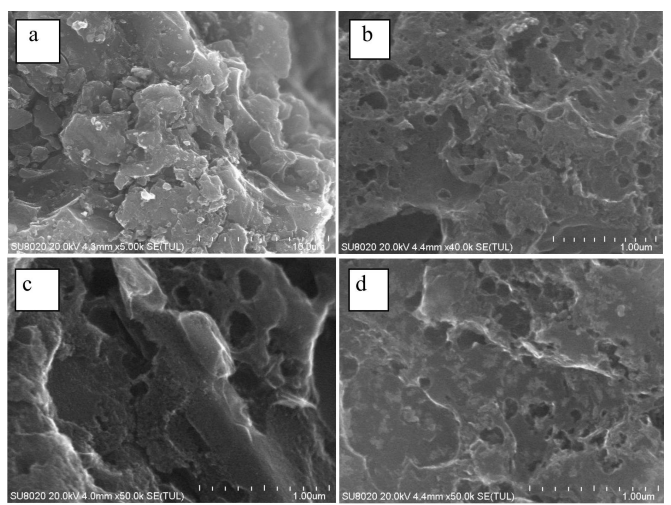

Fig. 5. SEM images of activated carbons DTO (a) DTO, (b) $\mathrm{DTO} / \mathrm{KOH}, \quad$ (c) $\mathrm{DTO} / \mathrm{ZnCl}_{2}$, (d) $\mathrm{DTO} / \mathrm{K}_{2} \mathrm{CO}_{3}$.

Figure 5a shows that the surface of DTO was relatively smooth without large cavities except for some occasional 
cracks or crevices. Figure 5b-d shows that the external surface of the $\mathrm{AC}$ samples prepared with $\mathrm{KOH}, \mathrm{ZnCl}_{2}$ or $\mathrm{K}_{2} \mathrm{CO}_{3}$ had larger cavities compared with the pristine DTO. The cavities occurring on the ACs were formed following the removal of the active agents, which when leaving had left the empty space. Consequently, the reaction with $\mathrm{KOH}, \mathrm{ZnCl}_{2}$ and $\mathrm{K}_{2} \mathrm{CO}_{3}$ was conducive to the creation of the porous structure and was proved to be an effective activating agent for the production of a high-surface area AC.

\section{5. $\mathrm{CO}_{2}$ adsorption}

The high pressure $\mathrm{CO}_{2}$ adsorption isotherms of the AC samples are presented in Fig. 6. All the isotherms and adsorption capacities are presented as mmol $\mathrm{CO}_{2} / \mathrm{g}$ carbon.
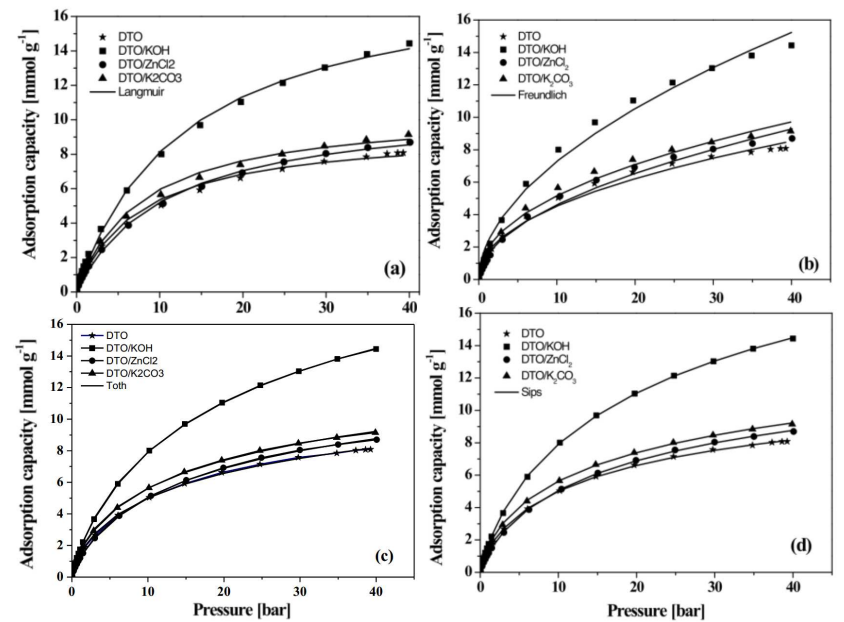

Fig. 6. Curve fitting with (a) Langmuir, (b) Freundlich, (c) Toth and (d) Sips models of $\mathrm{CO}_{2}$ adsorption isotherms onto activated carbons.

With the increase of $\mathrm{CO}_{2}$ pressure, the adsorbed $\mathrm{CO}_{2}$ volume increases sharply at low pressures before a slower increase occurs in the medium- and high-pressure ranges. This suggests that a $\mathrm{CO}_{2}$ molecule preferably adsorbs at high binding energy sites in carbon micropores [44].

Modifications of DTO resulted in an increase of $\mathrm{CO}_{2}$ adsorption. The $\mathrm{AC}$ sample activated with $\mathrm{KOH}$ showed the maximum $\mathrm{CO}_{2}$ adsorption capacity of $14.44 \mathrm{mmol} / \mathrm{g}$. The improvement in $\mathrm{CO}_{2}$ adsorption of the $\mathrm{DTO} / \mathrm{KOH}$ contributed to the abundant formation of micropores and the largest BET surface area.

The ACs prepared with $\mathrm{K}_{2} \mathrm{CO}_{3}$ and $\mathrm{ZnCl}_{2}$ exhibited a higher adsorption capacity of up to $8.70 \mathrm{mmol} / \mathrm{g}$ and $9.15 \mathrm{mmol} / \mathrm{g}$, respectively, compared with the commercial $\mathrm{AC}(8.08 \mathrm{mmol} / \mathrm{g})$. Using the $\mathrm{CO}_{2}$ adsorption capacity values (Fig. 6), a classification of ACs depending on the activating agent can be formulated: $\mathrm{KOH}>\mathrm{K}_{2} \mathrm{CO}_{3}>\mathrm{ZnCl}_{2}>$ DTO.

The Langmuir (Eq. (1)), Freundlich (Eq. (2)), Sips (Eq. (3)) and Toth (Eq. (4)) adsorption models were used to fit experimental data of $\mathrm{CO}_{2}$ adsorption onto the DTO-activated carbons, as shown in Fig. 6 .

Lines in Fig. 6 show the Freundlich, Langmuir, Sips and Toth isotherms used to describe the adsorption values. The experimental data were presented by symbols. The parameters of the Langmuir, Freundlich, Sips and Toth isotherms recovered from a nonlinear fit to experimental data are shown in Table IV.

TABLE IV

Langmuir, Freundlich, Sips and Toth isotherm model parameters and correlation coefficients for adsorption of $\mathrm{CO}_{2}$ on DTO - activated carbons.

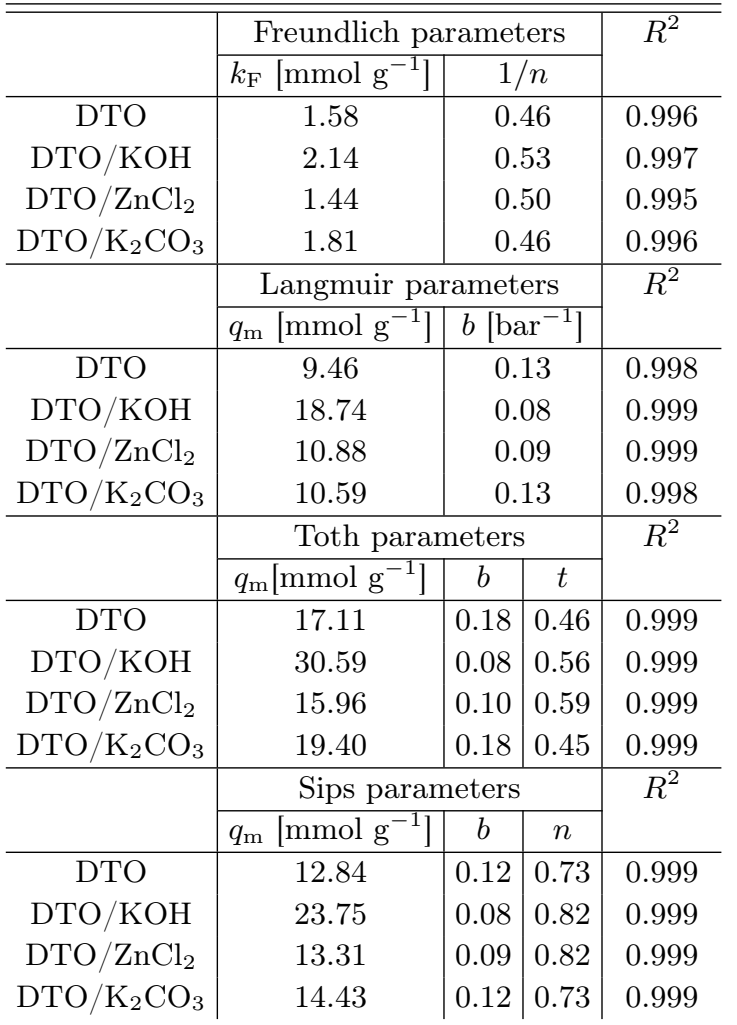

According to the $R^{2}$ parameter the Sips and Toth isotherms give satisfactory results. Both models are equally good. Therefore, the SSE, HYBRID, ARE, MPSD and chi-square error function were used to decide which of the two models proved to be better.

In order to analyze the impact of various error functions on the predicted isotherms, SSE, HYBRID, ARE, MPSD and chi-square were determined. Their values are presented in Table V.

The best fit isotherm was selected based on the error functions that produced the minimum error distribution between the predicted and experimental isotherms.

From Table V, the error functions corresponding to the minimized deviations between the experimental equilibrium data and predicted isotherms suggested Sips as the best fit isotherm (the lowest values of the error functions).

The $\mathrm{CO}_{2}$ amount adsorbed at saturation conditions, as predicted by the Sips isotherm model for DTO, $\mathrm{DTO} / \mathrm{KOH}, \mathrm{DTO} / \mathrm{ZnCl}_{2}$ and $\mathrm{DTO} / \mathrm{K}_{2} \mathrm{CO}_{3}$ was 12.84 , 
TABLE V

Error values of isotherm models for adsorption of $\mathrm{CO}_{2}$ by ACs.

\begin{tabular}{c|c|c|c|c|c}
\hline \hline & SSE & HYBRID & ARE & MPSD & $\begin{array}{c}\text { Chi- } \\
\text { square }\end{array}$ \\
\hline \multicolumn{5}{c}{ Langmuir } \\
\hline DTO & 1.1319 & 4.3311 & 18.7452 & 30.9081 & 1.7065 \\
DTO $/ \mathrm{KOH}$ & 0.9465 & 3.4477 & 13.0929 & 21.3003 & 0.5172 \\
DTO $/ \mathrm{ZnCl}_{2}$ & 0.3649 & 2.1244 & 13.2587 & 22.6063 & 0.3187 \\
DTO $/ \mathrm{K}_{2} \mathrm{CO}_{3}$ & 1.0634 & 4.9228 & 16.8774 & 28.2853 & 1.2600 \\
\hline \multicolumn{5}{c}{ Freundlich } \\
\hline DTO & 1.6728 & 5.6293 & 24.8187 & 53.4372 & 0.7738 \\
DTO $/ \mathrm{KOH}^{\prime}$ & 3.5954 & 13.8643 & 31.4015 & 67.8662 & 2.0796 \\
DTO $/ \mathrm{ZnCl}_{2}$ & 1.7306 & 9.7777 & 37.1571 & 91.0838 & 1.4666 \\
DTO $/ \mathrm{K}_{2} \mathrm{CO}_{3}$ & 1.6503 & 7.4289 & 23.4483 & 51.4734 & 0.7056 \\
\hline \multicolumn{5}{c}{ Sips } \\
\hline DTO & 0.0244 & 0.0812 & 2.5529 & 5.0181 & 0.0174 \\
DTO $/ \mathrm{KOH}$ & 0.0017 & 0.0162 & 0.9770 & 3.4620 & 0.0023 \\
DTO $/ \mathrm{ZnCl}_{2}$ & 0.0081 & 0.0153 & 0.7969 & 1.2252 & 0.0021 \\
DTO $/ \mathrm{K}_{2} \mathrm{CO}_{3}$ & 0.0065 & 0.0211 & 0.8243 & 1.5519 & 0.0030 \\
\hline \multicolumn{5}{c}{ Toth } \\
\hline DTO & 0.0777 & 0.4837 & 6.8357 & 15.9680 & 0.1433 \\
DTO $/ \mathrm{KOH}^{\circ}$ & 0.0231 & 0.1318 & 2.7670 & 6.3055 & 0.0185 \\
DTO $/ \mathrm{ZnCl}_{2}$ & 0.0282 & 0.1631 & 4.3260 & 10.7656 & 0.0228 \\
DTO $/ \mathrm{K}_{2} \mathrm{CO}_{3}$ & 0.0398 & 0.2934 & 4.3642 & 10.8022 & 0.0530 \\
\end{tabular}

$23.75,13.31$, and $14.43 \mathrm{mmol} / \mathrm{g}$, respectively. The single component surfaces obtained from the global fittings are in excellent agreement with the experimental data.

The Sips model assumes the surface of an adsorbent is heterogeneous [45] and a higher value of constant $b$ in the Sips isotherm equation indicates a stronger adsorption affinity [46]. In addition, it can be seen that the order of the value of $b$ for $\mathrm{CO}_{2}$ on carbons is: DTO and DTO $/ \mathrm{K}_{2} \mathrm{CO}_{3}>\mathrm{DTO} / \mathrm{ZnCl}_{2}>\mathrm{DTO} / \mathrm{KOH}$. Thus, the largest bounded is in $\mathrm{DTO} / \mathrm{KOH}$ - activated carbon.

The inhomogeneity of the adsorbent surface is described by the parameter $n$ in the Sips isotherm equation, with $0<n \leq 1$; the smaller the value of $n$ is, the less homogeneous is the surface. The $n$ value for $\mathrm{DTO} / \mathrm{K}_{2} \mathrm{CO}_{3}$ - activated carbon and pristine DTO carbon is equal (Table IV), which shows that the modification did not change the surface homogeneity. The $n$ value for DTO equals 0.73 , which suggest that the surface is rather homogeneous. The use of $\mathrm{KOH}$ and $\mathrm{ZnCl}_{2}$ in the modified DTO increased the homogeneity of the surface $(n=0.82)$.

\section{Conclusions}

The ACs were prepared by modifying DTO carbon with $\mathrm{K}_{2} \mathrm{CO}_{3}, \mathrm{ZnCl}_{2}$ and $\mathrm{KOH}$. The activating agent influenced the textural characteristics of the ACs. The best activating agent for DTO carbon as a $\mathrm{CO}_{2}$ adsorbent was $\mathrm{KOH}$. The resulting materials were characterized by a high specific surface area (up to $2063 \mathrm{~m}^{2} / \mathrm{g}$ ) and a large pore volume $\left(1.132 \mathrm{~cm}^{3} / \mathrm{g}\right)$. The BET surface area and porosity increased in this order: $\mathrm{KOH}>\mathrm{ZnCl}_{2}>\mathrm{K}_{2} \mathrm{CO}_{3}$. The mentioned modifications significantly improved the adsorption properties of the carbons, especially the volume of micropores, which is essential for enlarging the $\mathrm{CO}_{2}$ uptake at ambient conditions. The $\mathrm{CO}_{2}$ adsorption capacity of $14.44 \mathrm{mmol} / \mathrm{g}$ obtained for DTO/KOHmodified carbons was higher than that for other carbons. Experimental results were analyzed through the Langmuir, Freundlich, Toth and Sips adsorption isotherm model equations. It was found that the Sips model can satisfactorily describe the experimental isotherm data of $\mathrm{CO}_{2}$ adsorption on the ACs.

This work shows that the modification of a commercial carbon can be a feasible way for the development of adsorbents essential for some environmental applications, such as $\mathrm{CO}_{2}$ capture.

\section{Acknowledgments}

The research leading to these results has received funding from the Polish-Norwegian Research Programme operated by the National Centre for Research and Development under the Norwegian Financial Mechanism 2009-2014 in the frame of Project Contract No. PolNor $/ 237761 / 98 / 2014$.

\section{References}

[1] K. Wenelska, B. Michalkiewicz, J. Gong, T. Tang, R. Kaleńczuk, X. Chen, E. Mijowska, Int. J. Hydrogen Energ. 38, 16179 (2013).

[2] B. Michalkiewicz, J. Majewska, G. Kądziołka, K. Bubacz, S. Mozia, A.W. Morawski, J. $\mathrm{CO}_{2}$ Util. 5, 47 (2014).

[3] J. Sreńscek-Nazzal, U. Narkiewicz, A.W. Morawski, R.J. Wróbel, B. Michalkiewicz, J. Chem. Eng. Data 60, 3148 (2015).

[4] H. Kim, J. Lee, S. Lee, I.B. Lee, J. Park, J. Han, Energy 88, 756 (2015).

[5] B. Michalkiewicz, Z.C. Koren, J. Porous Mater. 22, 635 (2015).

[6] A. Heidari, H. Younesi, A. Rashidi, A. Ghoreyshi, J. Taiwan Inst. Chem. Eng. 45, 579 (2014).

[7] Z. Chen, S. Deng, H. Wei, B. Wang, J. Huang, G. Yu, Front. Environ. Sci. Eng. 7, 326 (2013).

[8] M.S. Shafeeyan, W.M. Ashri, W. Daud, A. Houshmand, A. Shamiri, J. Anal. Appl. Pyrolysis 89, 143 (2010).

[9] K.S.W. Sing, D.H. Everett, R.A.W. Haul, L. Moscou, R.A. Pierotti, J. Rouquerol, T. Siemieniewska, Pure Appl. Chem. 57, 603 (1985).

[10] J. Sreńscek-Nazzal, B. Michalkiewicz, Pol. J. Chem. Technol. 13, 63 (2011).

[11] J. Sreńscek-Nazzal, W. Kamińska, B. Michalkiewicz, Z.C. Koren, Ind. Crops Prod. 47, 153 (2013).

[12] J. Hayashia, T. Horikawa, I. Takeda, K. Muroyama, F.N. Ani, Carbon 40, 2381 (2002).

[13] M.A. Lillo-Rodena, D. Cazorla-Amoros, A. LinaresSolano, Carbon 41, 267 (2003). 
[14] A. Sayari, Y. Belmabkhout, R. Serna-Guerrero, Chem. Eng. J. 171, 760 (2011).

[15] J. Alcaniz-Monge, J.P. Marco-Lozar, M.A. LilloRodenas, Fuel Process. Technol. 92, 915 (2011).

[16] X. Hu, M. Radosz, K.A. Cychosz, M. Thommes, Environ. Sci. Technol. 45, 7068 (2011).

[17] A. Wahby, J.M. Ramos-Fernandez, M. MartínezEscandell, A. Sepulveda-Escribano, J. SilvestreAlbero, F. Rodríguez-Reinoso, Chem. Sus. Chem. 3, 974 (2010).

[18] M.M. Maroto-Valer, Z. Tang, Y.Z. Zhang, Fuel Process. Technol. 86, 1487 (2005).

[19] M. Olivares-Marin, M.M. Maroto-Valer, Fuel Process. Technol. 92, 322 (2011).

[20] M.G. Plaza, C. Pevida, C.F. Martin, J. Fermoso, J.J. Pis, F. Rubiera, Sep. Pur. Tech. 71, 102 (2010).

[21] M.G. Plaza, C. Pevida, B. Arias, J. Fermoso, M.D. Casal, C.F. Martin, F. Rubiera, J.J. Pis, Fuel 88, 2442 (2009).

[22] J.A. Thote, K.S. Iyer, R. Chatti, N.K. Labhsetwar, R.B. Biniwale, S.S. Rayalu, Carbon 48, 396 (2010).

[23] T.C. Drage, A. Arenillas, K.M. Smith, C. Pevida, S. Piippo, C.E. Snape, Fuel 86, 22 (2007)

[24] A. Busch, B.M. Krooss, Y. Gensterblum, F. Bergen, H.J.M. Pagnier, J. Geochem. Explor. 78, 671 (2003).

[25] B. Michalkiewicz, Appl. Catal. A Gen. 307, 270 (2006).

[26] B.H. Hameed, D.K. Mahmoud, A.L. Ahmad, J. Hazard. Mater. 158, 65 (2008).

[27] K.Y. Foo, B.H. Hameed, Chem. Eng. J. 156, 2 (2010).

[28] M. Salmasi, S. Fatemi, M.D. Rad, F. Jadidi, Int. J. Environ. Sci. Technol. 10, 1067 (2013).

[29] A. Behvandi, S. Tourani, World Academy of Science, Eng. Technol. 52, 617 (2011).
[30] K.V. Kumara, K. Porkodi, F. Rocha, J. Hazard. Mater. 150, 158 (2008).

[31] J.F. Porter, G. McKay, K.H. Choy, Chem. Eng. Sci. 54, 5863 (1999).

[32] D.W. Marquardt, J. Soc. Ind. Appl. Math. 11, 431 (1963).

[33] A. Jumasiah, T.G. Chuah, J. Gimbon, T.S.Y. Choong, I. Azni, Desalination 186, 57 (2005).

[34] L.M. Sikhwivhilu, S.S. Ray, N.J. Coville, Appl. Phys. A 94, 963 (2009).

[35] C. Murugan, H.C. Bajaj, R.V. Jasra, Catal. Lett. 137, 224 (2010).

[36] J. Lach, S. Biniak, M. Walczyk, Wegiel aktywny w ochronie środowiska i przemyśle 59, 62 (2006).

[37] Y. Li, M. Zijll, S. Chiang, N. Pan, J. Power. Sour. 196, 6003 (2011)

[38] M. Veres, M. Fule, S. Toth, M. Koos, I. Pocsik, Diamond Relat. Mater. 13, 1412 (2004).

[39] A. Janes, H. Kurig, E. Lust, Carbon 45, 1226 (2007).

[40] C. Guan, L.S. Loo, K. Wang, C. Yang, Energy Convers. Manage. 52, 1258 (2011).

[41] R. Kumar, R.S. Tiwari, O.N. Srivastava, Nano. Res. Lett. 6, 92 (2011).

[42] F. Tuinstra, J.L. Koenig, J. Chem. Phys. 53, 3 (1970).

[43] J. Qiu, Y. Li, Y. Wang, C. Liang, T. Wang, D. Wang, Carbon 41, 767 (2003).

[44] J. Ma, Ch. Si, Y. Li, R. Li, Adsorption 18, 503 (2012).

[45] W. Shao, L. Zhang, L. Li, R.L. Lee, Adsorption 15 497 (2009).

[46] P. Ning, F. Li, H. Yi, X. Tang, J. Peng, Y. Li, D. He, H. Deng, Sep. Pur. Tech. 98, 321 (2012). 